\title{
Iterative Methods for Pseudocontractive Mappings in Banach Spaces
}

\author{
Jong Soo Jung \\ Department of Mathematics, Dong-A University, Busan 604-714, Republic of Korea \\ Correspondence should be addressed to Jong Soo Jung; jungjs@dau.ac.kr
}

Received 12 February 2013; Accepted 3 March 2013

Academic Editor: Yisheng Song

Copyright (C) 2013 Jong Soo Jung. This is an open access article distributed under the Creative Commons Attribution License, which permits unrestricted use, distribution, and reproduction in any medium, provided the original work is properly cited.

Let $E$ a reflexive Banach space having a uniformly Gâteaux differentiable norm. Let $C$ be a nonempty closed convex subset of $E, T: C \rightarrow C$ a continuous pseudocontractive mapping with $F(T) \neq \emptyset$, and $A: C \rightarrow C$ a continuous bounded strongly pseudocontractive mapping with a pseudocontractive constant $k \in(0,1)$. Let $\left\{\alpha_{n}\right\}$ and $\left\{\beta_{n}\right\}$ be sequences in $(0,1)$ satisfying suitable conditions and for arbitrary initial value $x_{0} \in C$, let the sequence $\left\{x_{n}\right\}$ be generated by $x_{n}=\alpha_{n} A x_{n}+\beta_{n} x_{n-1}+\left(1-\alpha_{n}-\beta_{n}\right) T x_{n}, n \geq 1$. If either every weakly compact convex subset of $E$ has the fixed point property for nonexpansive mappings or $E$ is strictly convex, then $\left\{x_{n}\right\}$ converges strongly to a fixed point of $T$, which solves a certain variational inequality related to $A$.

\section{Introduction and Preliminaries}

Throughout this paper, we denote by $E$ the norm $\|\cdot\|$ and $E^{*}$ a real Banach space and the dual space of $E$, respectively. Let $C$ be a nonempty closed convex subset of $E$. For the mapping $T: C \rightarrow C$, we denote the fixed point set of $T$ by $F(T)$; that is, $F(T)=\{x \in C: T x=x\}$.

Let $J$ denote the normalized duality mapping from $E$ into $2^{X^{*}}$ defined by

$$
J(x)=\left\{f \in E^{*}:\langle x, f\rangle=\|x\|\|f\|,\|f\|=\|x\|\right\}, \quad \forall x \in E,
$$

where $\langle\cdot, \cdot\rangle$ denotes the generalized duality pair between $E$ and $E^{*}$. Recall that the norm of $E$ is said to be Gâteaux differentiable if

$$
\lim _{t \rightarrow 0} \frac{\|x+t y\|-\|x\|}{t}
$$

exists for each $x, y$ in its unit sphere $U=\{x \in E:\|x\|=1\}$. Such an $E$ is called a smooth Banach space. The norm is said to be uniformly Gâteaux differentiable if for $y \in U$, the limit is attained uniformly for $x \in U$. The space $E$ is said to have a uniformly Fréchet differentiable norm (and $E$ is said to be uniformly smooth) if the limit in (2) is attained uniformly for $(x, y) \in U \times U$. It is known that $E$ is smooth if and only if the normalized duality mapping $J$ is single valued. It is well known that if $E$ is uniformly smooth, then the duality mapping is norm-to-norm uniformly continuous on bounded subsets of $E$, and that if $E$ has a uniformly Gâteaux differentiable norm, then $J$ is norm-to-weak ${ }^{*}$ uniformly continuous on each bounded subsets of $E[1,2]$.

It is relevant to the results of this paper to note that while every uniformly smooth Banach space is a reflexive Banach space having a uniformly Gâteaux differentiable norm, the converse does not hold. To see this, consider $E$ to be the direct $\operatorname{sum} l^{2}\left(l^{p_{n}}\right)$, the class of all those sequences $x=\left\{x_{n}\right\}$ with $x_{n} \in$ $l^{p_{n}}$ and $\|x\|=\left(\sum_{n<\infty}\left\|x_{n}\right\|^{2}\right)^{1 / 2}$ (see [3]). If $1<p_{n}<\infty$ for $n \epsilon$ $\mathbb{N}$, where either $\lim \sup _{n \rightarrow \infty} p_{n}=\infty$ or $\liminf \inf _{n \rightarrow \infty} p_{n}=1$, then $E$ is a reflexive Banach space with a uniformly Gâteaux differentiable norm but is not uniformly smooth (see [3-5]). We also observe that the spaces which enjoy the fixed point property (shortly, F.P.P) for nonexpansive mappings are not necessarily spaces having a uniformly Gâteaux differentiable norm. On the other hand, the converse of this fact appears to be unknown as well.

A Banach space $E$ is said to be strictly convex if

$$
\|x\|=\|y\|=1, \quad x \neq y \text { implies } \frac{\|x+y\|}{2}<1 .
$$


A Banach space $E$ is said to be uniformly convex if $\delta_{E}(\varepsilon)>0$ for all $\varepsilon>0$, where $\delta_{E}(\varepsilon)$ is the modulus of convexity of $E$ defined by

$$
\begin{array}{r}
\delta_{E}(\varepsilon)=\inf \left\{1-\frac{\|x+y\|}{2}:\|x\| \leq 1,\|y\| \leq 1,\|x-y\| \geq \varepsilon\right\}, \\
\varepsilon \in[0,2] .
\end{array}
$$

It is well known that a uniformly convex Banach space $E$ is reflexive and strictly convex [1] and satisfies the F.P.P. for nonexpansive mappings. However, it appears to be unknown whether a reflexive and strictly convex space satisfies the F.P.P. for nonexpansive mappings.

Recall that a mapping $T$ with domain $D(T)$ and range $R(T)$ in $E$ is called pseudocontractive if the inequality

$$
\|x-y\| \leq\|x-y+r((I-T) x-(I-T) y)\|
$$

holds for each, $y \in D(T)$ and for all $r>0$. From a result of Kato [6], we know that (5) is equivalent to (6) below; there exists $j(x-y) \in J(x-y)$ such that

$$
\langle T x-T y, j(x-y)\rangle \leq\|x-y\|^{2}
$$

for all $x, y \in D(T)$. The mapping $T$ is said to be strongly pseudocontractive it there exists a constant $k \in(0,1)$ and $j(x-y) \in$ $J(x-y)$ such that

$$
\langle T x-T y, j(x-y)\rangle \leq k\|x-y\|^{2}
$$

for all $x, y \in D(T)$.

The class of pseudocontractive mappings is one of the most important classes of mappings in nonlinear analysis and it has been attracting mathematician's interest. In addition to generalizing the nonexpansive mappings (the mappings $T: D \rightarrow E$ for which $\|T x-T y\| \leq\|x-y\|$, for all $x, y \in D)$, the pseudocontractive ones are characterized by the fact that $T$ is pseudocontractive if and only if $I-T$ is accretive, where a mapping $A$ with domain $D(A)$ and range $R(A)$ in $E$ is called accretive if the inequality

$$
\|x-y\| \leq\|x-y+s(A x-A y)\|,
$$

holds for every $x, y \in D(A)$ and for all $s>0$.

Within the past 40 years or so, many authors have been devoting their study to the existence of zeros of accretive mappings or fixed points of pseudocontractive mappings and iterative construction of zeros of accretive mappings and of fixed points of pseudocontractive mappings (see [5, 7-10]). Also, several iterative methods for approximating fixed points (zeros) of nonexpansive and pseudocontractive mappings (accretive mappings) in Hilbert spaces and Banach spaces have been introduced and studied by many authors. We can refer to [11-17] and the references in therein.

In 2007, Rafiq [15] introduced a Mann-type implicit iterative method (9) for a hemicontractive mapping $T$ as

$$
x_{0} \in K, \quad x_{n}=\alpha_{n} x_{n-1}+\left(1-\alpha_{n}\right) T x_{n}, \quad \forall n \geq 1,
$$

where $K$ is a compact convex subset of a real Hilbert space $H$ and $\left\{\alpha_{n}\right\} \subset[\delta, 1-\delta]$ for some $\delta \in(0,1)$, and proved that $\left\{x_{n}\right\}$ converges strongly to a fixed point of $T$.

In 2007, Yao et al. [16] introduced an iterative method (10) below for approximating fixed points of a continuous pseudocontractive mapping $T$ without compactness assumption on its domain in a uniformly smooth Banach space: for arbitrary initial value $x_{0} \in C$ and a fixed anchor $u \in C$,

$$
x_{n}=\alpha_{n} u+\beta_{n} x_{n-1}+\gamma_{n} T x_{n}, \quad \forall n \geq 1,
$$

where $\left\{\alpha_{n}\right\},\left\{\beta_{n}\right\}$, and $\left\{\gamma_{n}\right\}$ are three sequences in $(0,1)$ satisfying some appropriate conditions. By using the Reich inequality [9] in uniformly smooth Banach spaces

$$
\begin{aligned}
\|x+y\|^{2} \leq & \|x\|^{2}+2\langle y, J(x)\rangle \\
& +\max \{\|x\|, 1\}\|y\| b(\|y\|), \quad \forall x, y \in E,
\end{aligned}
$$

where $b:[0, \infty) \rightarrow[0, \infty)$ is a nondecreasing continuous function, they proved that the sequence $\left\{x_{n}\right\}$ generated by (10) converges strongly to a fixed point of $T$. In particular, in 2007, by using the viscosity iterative method studied by $[18,19]$, Song and Chen [17] introduced a modified implicit iterative method (12) below for a continuous pseudocontractive mapping $T$ without compactness assumption on its domain in a real reflexive and strictly convex Banach space having a uniformly Gâteaux differentiable norm: for arbitrary initial value $x_{0} \in C$,

$$
\begin{gathered}
x_{n}=\alpha_{n} y_{n}+\left(1-\alpha_{n}\right) T x_{n}, \\
y_{n}=\beta_{n} f\left(x_{n-1}\right)+\left(1-\beta_{n}\right) x_{n-1}, \quad \forall n \geq 1,
\end{gathered}
$$

where $\left\{\alpha_{n}\right\}$ and $\left\{\beta_{n}\right\}$ are two sequences in $(0,1)$ satisfying some appropriate conditions and $f: C \rightarrow C$ is a contractive mapping, and proved that the sequence $\left\{x_{n}\right\}$ generated by (12) converges strongly to a fixed point of $T$, which is the unique solution of a certain variational inequality related to $f$.

In this paper, inspired and motivated by the abovementioned results, we introduce the following the iterative method for a continuous pseudocontractive mapping $T$ : for arbitrary initial value $x_{0} \in C$,

$$
x_{n}=\alpha_{n} A x_{n}+\beta_{n} x_{n-1}+\left(1-\alpha_{n}-\beta_{n}\right) T x_{n}, \quad \forall n \geq 1,
$$

where $\left\{\alpha_{n}\right\}$ and $\left\{\beta_{n}\right\}$ are two sequences in $(0,1)$ and $A$ : $C \rightarrow C$ is a bounded continuous strongly pseudocontractive mapping with a pseudocontractive constant $k \in(0,1)$. Whether a reflexive Banach space has a uniformly Gâteaux differentiable norm such that every weakly compact convex subset of $E$ has the fixed point property for nonexpansive mappings, or a reflexive and strict convex Banach space has a uniformly Gâteaux differentiable norm, we establish the strong convergence of the sequence generated by proposed iterative method (13) to a fixed point of the mapping, which solves a certain variational inequality related to $A$. The main result generalizes, improves, and develops the corresponding results of Yao et al. [16] and Song and Chen [17] as well as Rafiq [15].

We need the following well-known lemmas for the proof of our main result. 
Lemma 1 (see $[1,2])$. Let $E$ be a Banach space and let $J$ be the normalized duality mapping on $E$. Then for any $x, y \in E$, the following inequality holds:

$$
\|x+y\|^{2} \leq\|x\|^{2}+2\langle y, j(x+y)\rangle, \quad \forall j(x+y) \in J(x+y) .
$$

Lemma 2 (see [20]). Let $\left\{s_{n}\right\}$ be a sequence of nonnegative real numbers satisfying

$$
s_{n+1} \leq\left(1-\lambda_{n}\right) s_{n}+\lambda_{n} \delta_{n}, \quad \forall n \geq 0,
$$

where $\left\{\lambda_{n}\right\}$ and $\left\{\delta_{n}\right\}$ satisfy the following conditions:

(i) $\left\{\lambda_{n}\right\} \subset[0,1]$ and $\sum_{n=0}^{\infty} \lambda_{n}=\infty$ or, equivalently, $\prod_{n=0}^{\infty}\left(1-\lambda_{n}\right)=0$,

(ii) $\lim \sup _{n \rightarrow \infty} \delta_{n} \leq 0$ or $\sum_{n=0}^{\infty} \lambda_{n} \delta_{n}<\infty$.

Then $\lim _{n \rightarrow \infty} s_{n}=0$.

\section{Iterative Methods}

We need the following result which was given in [10].

Proposition 3. Let $C$ be a closed convex subset of a Banach space $E$. Suppose that $T, A$ are two continuous mappings from $C$ into itself, which are pseudocontractive and strongly pseudocontractive, respectively. Then there exists a unique path $t \mapsto$ $x_{t} \in C, t \in(0,1)$, satisfying

$$
x_{t}=t A x_{t}+(1-t) T x_{t} .
$$

Further, the following hold.

(i) Suppose that there exists a bounded sequence $\left\{x_{n}\right\}$ in $C$ such that $x_{n}-T x_{n} \rightarrow 0$, while $\left\{x_{n}-A x_{n}\right\}$ is bounded. Then the path $\left\{x_{t}\right\}$ is bounded.

(ii) In particular, if $T$ has a fixed point in $C$, then the path $\left\{x_{t}\right\}$ is bounded.

(iii) If $p$ is a fixed point of $T$, there exists $j \in J\left(x_{t}-p\right)$ such that

$$
\left\langle x_{t}-A x_{t}, j\right\rangle \leq 0 \text {. }
$$

We prepare the following result for the existence of a solution of the variational inequality related to $A$.

Theorem 4. Let $C$ be a nonempty closed convex subset of a Banach space $E$ and let $T$ be a continuous pseudocontractive mapping from $C$ into itself with $F(T) \neq \emptyset$ and let $A: C \rightarrow C$ be a continuous bounded strongly pseudocontractive mapping with a pseudocontractive coefficient $k \in(0,1)$. For each $t \in$ $(0,1)$, let $x_{t} \in C$ be defined by

$$
x_{t}=t A x_{t}+(1-t) T x_{t} .
$$

If one of the following assumptions holds:

(H1) $E$ is a reflexive Banach space, the norm of $E$ is uniformly Gâteaux differentiable, and every weakly compact convex subset of $E$ has the fixed point property for nonexpansive mappings;
$(\mathrm{H} 2) E$ is a reflexive and strictly convex Banach space and the norm of $E$ is uniformly Gâteaux differentiable,

then the path $\left\{x_{t}\right\}$ converges strongly to a point $u$ in $F(T)$, which is the unique solution of the variational inequality

$$
\langle(I-A) u, J(u-v)\rangle \leq 0, \quad \forall v \in F(T) .
$$

Proof. In case of (H1), the result follows from Theorem 2 of [10]. So, we prove only the case of $(\mathrm{H} 2)$. We follow the method of proof in $[5,10]$.

By Proposition 3, the path $\left\{x_{t}: t \in(0,1)\right\}$ exists. It remains to show that it converges strongly to a fixed point of $T$ as $t \rightarrow 0$. As a consequence of Theorem 6 of [21], the mapping $2 I-T$ has a nonexpansive inverse, denoted by $g$, which maps $C$ into itself with $F(T)=F(g)$. By Proposition 3(ii), $\left\{x_{t}\right\}$ is bounded. Since $A$ is a bounded mapping, $\left\{A x_{t}: t \in(0,1)\right\}$ is bounded. From (18), we have

$$
\left\|T x_{t}\right\|=\left\|\frac{1}{1-t} x_{t}-\frac{t}{1-t} A x_{t}\right\| \leq \frac{1}{1-t}\left\|x_{t}\right\|+\frac{t}{1-t}\left\|A x_{t}\right\|,
$$

and so $\left\{T x_{t}\right\}$ is bounded (as $t \rightarrow 0$ ). Since

$$
\left\|x_{t}-T x_{t}\right\|=t\left\|A x_{t}-T x_{t}\right\| \longrightarrow 0 \text { as } t \longrightarrow 0,
$$

we derive that

$$
x_{t}-g x_{t} \longrightarrow 0 \text { as } t \longrightarrow 0 \text {. }
$$

Let $\left\{t_{n}\right\}$ be a sequence in $(0,1)$ such that $t_{n} \rightarrow 0$ as $n \rightarrow \infty$ and let $x_{n}=x_{t_{n}}$. Since $\left\{x_{n}\right\}$ is bounded, we may define $f: C \rightarrow \mathbb{R}^{+}$by $f(x)=\limsup _{n \rightarrow \infty}\left\|x_{n}-x\right\|$. Since $E$ is reflexive, $f(x) \rightarrow \infty$ as $\|x\| \rightarrow \infty$, and $f$ is continuous and convex, and the set

$$
M=\{u \in C: f(u)=\inf \{f(x): x \in C\}\}
$$

is a nonempty (due to Theorem 1.2 of [22]). Since $F(T)=$ $F(g) \neq \emptyset$, let $v \in F(g)$. Then, since $E$ is strict convex, the set

$$
M_{0}=\{u \in M:\|u-v\|=\inf \{\|x-v\|: x \in M\}\}
$$

is singleton. Let $M_{0}=\{u\}$ for some $u \in M$. We also know that $g(v)=v$ and

$$
\|g(u)-v\|=\|g(u)-g(v)\| \leq\|u-v\| .
$$

Therefore, $g(u)=u$. Since $T$ is pseudocontractive and $u$ is a fixed point of $T$, we derive from Proposition 3(iii) that

$$
\left\langle x_{n}-A x_{n}, J\left(x_{n}-u\right)\right\rangle \leq 0, \quad \forall n \in \mathbb{N} .
$$

Now let $x=A u-u$ and $t \in(0,1)$. Then by Lemma 1 , we have

$$
\left\|x_{n}-u-t x\right\|^{2} \leq\left\|x_{n}-u\right\|^{2}+2\left\langle-t x, J\left(x_{n}-u-t x\right)\right\rangle .
$$

Let $\varepsilon>0$. Then by the assumption on $E$, there exists $\delta>0$ such that $u+t x \in C$ and

$$
\left\langle x, J\left(x_{n}-u\right)\right\rangle<\varepsilon+\left\langle x, J\left(x_{n}-u-t x\right)\right\rangle
$$


for all $t \in(0, \delta)$. Consequently,

$$
\left\langle x, J\left(x_{n}-u\right)\right\rangle<\varepsilon+\frac{1}{2 t}\left[\left\|x_{n}-u\right\|^{2}-\left\|x_{n}-u-t x\right\|^{2}\right] .
$$

Therefore, we may choose a subsequence $\left\{x_{n_{k}}\right\}$ of $\left\{x_{n}\right\}$ such that

$$
\limsup _{k \rightarrow \infty}\left\langle A u-u, J\left(x_{n_{k}}-u\right)\right\rangle \leq 0 .
$$

From (26) and the fact that $A$ is strongly pseudocontractive, we have

$$
\begin{aligned}
\left\|x_{n_{k}}-u\right\|^{2}= & \left\langle x_{n_{k}}-u, J\left(x_{n_{k}}-u\right)\right\rangle \\
= & \left\langle x_{n_{k}}-A x_{n_{k}}, J\left(x_{n_{k}}-u\right)\right\rangle \\
& +\left\langle A x_{n_{k}}-A u, J\left(x_{n_{k}}-u\right)\right\rangle \\
& +\left\langle A u-u, J\left(x_{n_{k}}-u\right)\right\rangle \\
\leq & k\left\|x_{n_{k}}-u\right\|^{2}+\left\langle A u-u, J\left(x_{n_{k}}-u\right)\right\rangle,
\end{aligned}
$$

which implies that $(1-k)\left\|x_{n_{k}}-u\right\|^{2} \leq\left\langle A u-u, J\left(x_{n_{k}}-u\right)\right\rangle$. Thus, by (30), we conclude that $\left\{x_{n_{k}}\right\}$ converges strongly to $u$. To prove that actually the net $\left\{x_{t}\right\}$ converges strongly to $u$, let $\left\{x_{m_{k}}\right\}$ be another subsequence of $\left\{x_{t}: t \in(0,1)\right\}$ such that $x_{m_{k}}=x_{t_{m_{k}}}, t_{m_{k}} \rightarrow 0$ as $k \rightarrow \infty$ and $x_{m_{k}} \rightarrow v$, where $T v=v$. Then Proposition 3(iii) implies that $\langle u-A u, J(u-v)\rangle \leq 0$ and $\langle v-A v, J(v-u)\rangle \leq 0$. This implies that

$$
\langle u-v-(A u-A v), J(u-v)\rangle \leq 0 .
$$

Since $A$ is strongly pseudocontractive, $u=v$ and the strong $\lim _{t \rightarrow 0} x_{t}$ exists. This same argument may be used to conclude that $u$ is the only solution of the variational inequality (19). This completes the proof.

Using Theorem 4, we establish our second main result.

Theorem 5. Let $E$ be a Banach space and let $C$ be a nonempty closed convex subset of E. Let $T: C \rightarrow C$ be a continuous pseudocontractive mapping such that $F(T) \neq \emptyset$, and let $A$ : $C \rightarrow C$ be a continuous bounded strongly pseudocontractive mapping with a pseudocontractive constant $k \in(0,1)$. Let $\left\{\alpha_{n}\right\}$ and $\left\{\beta_{n}\right\}$ be sequences in $(0,1)$ satisfying the following conditions:

(C1) $\lim _{n \rightarrow \infty} \alpha_{n}=0$ and $\lim _{n \rightarrow \infty} \beta_{n}=0$;

(C2) $\sum_{n=1}^{\infty}\left(\alpha_{n} /\left(\alpha_{n}+\beta_{n}\right)\right)=\infty$.

For arbitrary initial value $x_{0} \in C$, let the sequence $\left\{x_{n}\right\}$ be defined by

$$
x_{n}=\alpha_{n} A x_{n}+\beta_{n} x_{n-1}+\left(1-\alpha_{n}-\beta_{n}\right) T x_{n}, \quad \forall n \geq 1 .
$$

If one of the following assumptions holds:

(H1) $E$ is a reflexive Banach space, the norm of $E$ is uniformly Gâteaux differentiable, and every weakly compact convex subset of $E$ has the fixed point property for nonexpansive mappings;
(H2) $E$ is a reflexive and strictly convex Banach space and the norm of $E$ is uniformly Gâteaux differentiable,

then $\left\{x_{n}\right\}$ converges strongly to a fixed point $p$ of $T$, which is the unique solution of the variational inequality

$$
\langle(I-A) p, J(p-q)\rangle \leq 0, \quad \forall q \in F(T) .
$$

Proof. We divide the proof into several steps as follows.

Step 1. We show that $\left\{x_{n}\right\}$ is bounded. To this end, let $q \in$ $F(T)$. Then, noting that

$$
\begin{gathered}
x_{n}-q=\alpha_{n}\left(A x_{n}-q\right)+\beta_{n}\left(x_{n-1}-q\right) \\
+\left(1-\alpha_{n}-\beta_{n}\right)\left(T x_{n}-q\right), \\
\left\langle T x_{n}-q, J\left(x_{n}-q\right)\right\rangle \leq\left\|x_{n}-q\right\|^{2} \\
\left.A x_{n}-A q, J\left(x_{n}-q\right)\right\rangle \leq k\left\|x_{n}-q\right\|^{2},
\end{gathered}
$$

we have

$$
\begin{aligned}
\left\|x_{n}-q\right\|^{2}= & \left\langle\alpha_{n}\left[\left(A x_{n}-A q\right)+(A q-q)\right]+\beta_{n}\left(x_{n-1}-q\right)\right. \\
& \left.+\left(1-\alpha_{n}-\beta_{n}\right)\left(T x_{n}-q\right), J\left(x_{n}-q\right)\right\rangle \\
\leq & \alpha_{n} k\left\|x_{n}-q\right\|^{2}+\alpha_{n}\|A q-q\|\left\|x_{n}-q\right\| \\
& +\beta_{n}\left\|x_{n-1}-q\right\|\left\|x_{n}-q\right\| \\
& +\left(1-\alpha_{n}-\beta_{n}\right)\left\|x_{n}-q\right\|^{2},
\end{aligned}
$$

which implies

$$
\begin{aligned}
\left\|x_{n}-q\right\| \leq & \left(1-\alpha_{n}(1-k)-\beta_{n}\right)\left\|x_{n}-q\right\| \\
& +\alpha_{n}\|A q-q\|+\beta_{n}\left\|x_{n-1}-q\right\| .
\end{aligned}
$$

So, we obtain

$$
\begin{aligned}
\left\|x_{n}-q\right\| \leq & \frac{\alpha_{n}}{(1-k) \alpha_{n}+\beta_{n}}\|A q-q\| \\
& +\frac{\beta_{n}}{(1-k) \alpha_{n}+\beta_{n}}\left\|x_{n-1}-q\right\| \\
= & \frac{(1-k) \alpha_{n}}{(1-k) \alpha_{n}+\beta_{n}} \frac{\|A q-q\|}{1-k} \\
& +\frac{\beta_{n}}{(1-k) \alpha_{n}+\beta_{n}}\left\|x_{n-1}-p\right\| \\
\leq & \max \left\{\left\|x_{n-1}-q\right\|, \frac{\|A q-q\|}{1-k}\right\} .
\end{aligned}
$$

By induction, we have

$$
\left\|x_{n}-q\right\| \leq \max \left\{\left\|x_{0}-q\right\|, \frac{1}{1-k}\|A q-q\|\right\} \quad \text { for } n \geq 1 .
$$


Hence, $\left\{x_{n}\right\}$ is bounded. Since $A$ is a bounded mapping, $\left\{A x_{n}\right\}$ is bounded. From (33), it follows that

$$
\left\|T x_{n}\right\|=\frac{1}{1-\alpha_{n}-\beta_{n}}\left(\left\|x_{n}\right\|+\alpha_{n}\left\|A x_{n}\right\|+\beta_{n}\left\|x_{n-1}\right\|\right),
$$

and so $\left\{T x_{n}\right\}$ is bounded (as $n \rightarrow \infty$ ).

Step 2. We show that $\lim _{n \rightarrow \infty}\left\|x_{n}-T x_{n}\right\|=0$. In fact, by (33) and the condition (C1), we have

$$
\left\|x_{n}-T x_{n}\right\| \leq \alpha_{n}\left\|A x_{n}-T x_{n}\right\|+\beta_{n}\left\|x_{n-1}-T x_{n}\right\| \longrightarrow 0 .
$$

Step 3. We show that

$$
\limsup _{n \rightarrow \infty}\left\langle A p-p, J\left(x_{n}-p\right)\right\rangle \leq 0
$$

where $p=\lim _{t \rightarrow 0} x_{t}$ with $x_{t} \in C$ being defined by $x_{t}=t A x_{t}+$ $(1-t) T x_{t}$. To this end, we note that

$$
\begin{aligned}
x_{t}-x_{n}= & t A x_{t}+(1-t) T x_{t}-x_{n} \\
= & t\left(A x_{t}-x_{t}\right)+\left(T x_{t}-x_{n}\right)-t\left(T x_{t}-x_{t}\right) \\
= & t\left(A x_{t}-x_{t}\right)+\left(T x_{t}-T x_{n}\right) \\
& +\left(T x_{n}-x_{n}\right)+t^{2}\left(A x_{t}-T x_{t}\right)
\end{aligned}
$$

Then, it follows that

$$
\begin{aligned}
\left\|x_{t}-x_{n}\right\|^{2}= & t\left\langle A x_{t}-x_{t}, J\left(x_{t}-x_{n}\right)\right\rangle \\
& +\left\langle T x_{t}-T x_{n}, J\left(x_{t}-x_{n}\right)\right\rangle \\
& +\left\langle T x_{n}-x_{n}, J\left(x_{t}-x_{n}\right)\right\rangle \\
& +t^{2}\left\langle A x_{t}-T x_{t}, J\left(x_{t}-x_{n}\right)\right\rangle \\
\leq & t\left\langle A x_{t}-x_{t}, J\left(x_{t}-x_{n}\right)\right\rangle+\left\|x_{t}-x_{n}\right\|^{2} \\
& +\left\|T x_{n}-x_{n}\right\|\left\|x_{t}-x_{n}\right\| \\
& +t^{2}\left\|A x_{t}-T x_{t}\right\|\left\|x_{t}-x_{n}\right\|,
\end{aligned}
$$

which implies that

$$
\begin{aligned}
\left\langle A x_{t}-x_{t}, J\left(x_{n}-x_{t}\right)\right\rangle \leq & \frac{\left\|T x_{n}-x_{n}\right\|}{t}\left\|x_{t}-x_{n}\right\| \\
& +t\left\|A x_{t}-T x_{t}\right\|\left\|x_{t}-x_{n}\right\| .
\end{aligned}
$$

From Proposition 3, we know that $\left\{x_{t}\right\},\left\{A x_{t}\right\}$ and $\left\{T x_{t}\right\}$, are bounded. Since $\left\{x_{n}\right\}$ and $\left\{T x_{n}\right\}$ are also bounded and $x_{n}-$ $T x_{n} \rightarrow 0$ by Step 2, taking the upper limit as $n \rightarrow \infty$ in (45), we get

$$
\limsup _{n \rightarrow \infty}\left\langle A x_{t}-x_{t}, J\left(x_{n}-x_{t}\right)\right\rangle \leq t L,
$$

where $L>0$ is a constant such that $\left\|A x_{t}-T x_{t}\right\|\left\|x_{t}-x_{n}\right\| \leq L$ for all $n \geq 0$ and $t \in(0,1)$. Taking the lim sup as $t \rightarrow 0$ in (46) and noticing the fact that the two limits are interchangeable due to the fact that $J$ is norm-to-weak ${ }^{*}$ uniformly continuous on each bounded subsets of $E$, we have

$$
\limsup _{n \rightarrow \infty}\left\langle A p-p, J\left(x_{n}-p\right)\right\rangle \leq 0 .
$$

Step 4. We show that $\lim _{n \rightarrow \infty}\left\|x_{n}-p\right\|=0$, where $p=$ $\lim _{t \rightarrow 0} x_{t}$ with $x_{t} \in C$ being defined by $x_{t}=t A x_{t}+(1-t) T x_{t}$ and $p$ is the unique solution of the variational inequality (34) by Theorem 4 . First, from (33) and (35), we have

$$
\begin{aligned}
\left\|x_{n}-p\right\|^{2}= & \left\langle x_{n}-p, J\left(x_{n}-p\right)\right\rangle \\
= & \left\langle\alpha_{n}\left(A x_{n}-p\right)+\beta_{n}\left(x_{n-1}-p\right)\right. \\
& \left.+\left(1-\alpha_{n}-\beta_{n}\right)\left(T x_{n}-p\right), J\left(x_{n}-p\right)\right\rangle \\
= & \left\langle\alpha_{n}\left(A x_{n}-A p\right), J\left(x_{n}-p\right)\right\rangle \\
& +\beta_{n}\left\langle x_{n-1}-p, J\left(x_{n}-p\right)\right\rangle \\
& +\left(1-\alpha_{n}-\beta_{n}\right)\left\langle T x_{n}-p, J\left(x_{n}-p\right)\right\rangle \\
& +\alpha_{n}\left\langle A p-p, J\left(x_{n}-p\right)\right\rangle \\
\leq & \alpha_{n} k\left\|x_{n}-p\right\|^{2}+\beta_{n}\left\|x_{n-1}-p\right\|\left\|x_{n}-p\right\| \\
& +\left(1-\alpha_{n}-\beta_{n}\right)\left\|x_{n}-p\right\|^{2} \\
& +\alpha_{n}\left\langle A p-p, J\left(x_{n}-p\right)\right\rangle \\
\leq & \alpha_{n} k\left\|x_{n}-p\right\|^{2}+\frac{\beta_{n}}{2}\left(\left\|x_{n-1}-p\right\|^{2}+\left\|x_{n}-p\right\|^{2}\right) \\
& +\left(1-\alpha_{n}-\beta_{n}\right)\left\|x_{n}-p\right\|^{2} \\
& +\alpha_{n}\left\langle A p-p, J\left(x_{n}-p\right)\right\rangle .
\end{aligned}
$$

This implies that

$$
\begin{aligned}
\left\|x_{n}-p\right\|^{2} \leq & \frac{\beta_{n}}{2(1-k) \alpha_{n}+\beta_{n}}\left\|x_{n-1}-p\right\|^{2} \\
& +\frac{2 \alpha_{n}}{2(1-k) \alpha_{n}+\beta_{n}}\left\langle A p-p, J\left(x_{n}-p\right)\right\rangle \\
= & \left(1-\frac{2(1-k) \alpha_{n}}{2(1-k) \alpha_{n}+\beta_{n}}\right)\left\|x_{n-1}-p\right\|^{2} \\
& +\frac{2(1-k) \alpha_{n}}{2(1-k) \alpha_{n}+\beta_{n}} \frac{\left\langle A p-p, J\left(x_{n}-p\right)\right\rangle}{1-k} \\
= & \left(1-\lambda_{n}\right)\left\|x_{n-1}-p\right\|^{2}+\lambda_{n} \delta_{n},
\end{aligned}
$$

where $\lambda_{n}=2(1-k) \alpha_{n} /\left(2(1-k) \alpha_{n}+\beta_{n}\right)$ and $\delta_{n}=(1 /(1-$ $k))\left\langle A p-p, J\left(x_{n}-p\right)\right\rangle$. We observe that $0 \leq 2(1-k) \alpha_{n} /(2(1-$ $\left.k) \alpha_{n}+\beta_{n}\right) \leq 1$ and $(1-k) \alpha_{n} /\left(\alpha_{n}+\beta_{n}\right)=2(1-k) \alpha_{n} /\left(2 \alpha_{n}+\right.$ $\left.2 \beta_{n}\right)<2(1-k) \alpha_{n} /\left(2(1-k) \alpha_{n}+\beta_{n}\right)$. From the condition (C2) and Step 3, it is easily seen that $\sum_{n=1}^{\infty} \lambda_{n}=\infty$ and $\lim \sup _{n \rightarrow \infty} \delta_{n} \leq 0$. Thus, applying Lemma 2 to (49), we conclude that $\lim _{n \rightarrow \infty} x_{n}=p$. This completes the proof. 
Corollary 6. Let E be a uniformly smooth Banach space and let $C$ be a nonempty closed convex subset of E. Let $T: C \rightarrow C$ be a continuous pseudocontractive mapping such that $F(T) \neq \emptyset$ and let $A: C \rightarrow C$ be a continuous bounded strongly pseudocontractive mapping with a pseudocontractive constant $k \in(0,1)$. Let $\left\{\alpha_{n}\right\}$ and $\left\{\beta_{n}\right\}$ be two sequences in $(0,1)$ satisfying the conditions (C1) and (C2) in Theorem 5. For arbitrary initial value $x_{0} \in C$, let the sequence $\left\{x_{n}\right\}$ be generated by (33) in Theorem 5. Then $\left\{x_{n}\right\}$ converges strongly to a fixed point $p$ of $T$, which is the unique solution of the variational inequality (34).

Corollary 7 (see [16, Theorem 3.1]). Let $E$ be a uniformly smooth Banach space and let $C$ be a nonempty closed convex subset of E. Let $T: C \rightarrow C$ be a continuous pseudocontractive mapping such that $F(T) \neq \emptyset$. Let $\left\{\alpha_{n}\right\},\left\{\beta_{n}\right\}$ and $\left\{\gamma_{n}\right\}$ be three sequences in $(0,1)$ satisfying the conditions (C1) and (C2) in Theorem 5 and $\gamma_{n}=1-\alpha_{n}-\beta_{n}$ for $n \geq 1$. For arbitrary initial value $x_{0} \in C$ and a fixed anchor $u \in C$, let the sequence $\left\{x_{n}\right\}$ be generated by

$$
x_{n}=\alpha_{n} u+\beta_{n} x_{n-1}+\gamma_{n} T x_{n}, \quad \forall n \geq 1 .
$$

Then $\left\{x_{n}\right\}$ converges strongly to a fixed point $p$ of $T$, which is the unique solution of the variational inequality

$$
\langle p-u, J(p-q)\rangle \leq 0, \quad \forall q \in F(T) .
$$

Proof. Taking $A x=u$, for all $x \in C$ as a constant function, the result follows from Corollary 6.

Corollary 8. Let $E$ be a uniformly convex Banach space has a uniformly Gâteaux differentiable norm and let $C$ be a nonempty closed convex subset of E. Let $T: C \rightarrow C$ be a continuous pseudocontractive mapping such that $F(T) \neq \emptyset$ and let $A: C \rightarrow C$ be a continuous bounded strongly pseudocontractive mapping with a pseudocontractive constant $k \in(0,1)$. Let $\left\{\alpha_{n}\right\}$ and $\left\{\beta_{n}\right\}$ be two sequences in $(0,1)$ satisfying the conditions (C1) and (C2) in Theorem 5. For arbitrary initial value $x_{0} \in C$, let the sequence $\left\{x_{n}\right\}$ be generated by (33) in Theorem 5. Then $\left\{x_{n}\right\}$ converges strongly to a fixed point $p$ of $T$, which is the unique solution of the variational inequality (34).

\section{Remark 9.}

(1) Theorem 5 extends and improves Theorem 3.1 of Yao et al. [16] in the following aspects.

(a) $u$ is replaced by a continuous bounded strongly pseudocontractive mapping $A$.

(b) The uniformly smooth Banach space is extended to a reflexive Banach space having a uniformly Gâteaux differentiable norm.

(c) The condition $\alpha_{n} / \beta_{n} \rightarrow 0$ in [16] is weakened to $\alpha_{n} \rightarrow 0$ and $\beta_{n} \rightarrow 0$ as $n \rightarrow \infty$.

(2) It is worth pointing out that in Corollaries 6 and 7, we do not use the Reich inequality (11) in comparison with Theorem 3.1 of Yao et al. [16].

(3) Theorem 5 and Corollary 8 also develop and complement Theorem 3.1 and Corollary 3.2 of Song and
Chen [17] by replacing the contractive mapping with a continuous bounded strongly pseudocontractive mapping in the iterative scheme (1.7) in [17].

(4) The assumption (H1) in Theorems 4 and 5 appears to be independent of the assumption ( $\mathrm{H} 2)$.

(5) We point out that the results in this paper apply to all $L^{p}$ spaces, $1<p<\infty$.

\section{Acknowledgment}

This study was supported by research funds from Dong-A University.

\section{References}

[1] R. P. Agarwal, D. O'Regan, and D. R. Sahu, Fixed Point Theory for Lipschitzian-Type Mappings with Applications, vol. 6, Springer, 2009.

[2] I. Cioranescu, Geometry of Banach Spaces, Duality Mappings and Nonlinear Problems, Kluwer Academic, Dordrecht, The Netherlands, 1990.

[3] M. M. Day, "Reflexive Banach spaces not isomorphic to uniformly convex spaces," Bulletin of the American Mathematical Society, vol. 47, pp. 313-317, 1941.

[4] V. Zizler, "On some rotundity and smoothness properties of Banach spaces," Dissertationes Mathematicae, vol. 87, pp. 5-33, 1971.

[5] C. H. Morales and J. S. Jung, "Convergence of paths for pseudocontractive mappings in Banach spaces," Proceedings of the American Mathematical Society, vol. 128, no. 11, pp. 3411-3419, 2000.

[6] T. Kato, "Nonlinear semigroups and evolution equations," Journal of the Mathematical Society of Japan, vol. 19, pp. 508-520, 1967.

[7] K. Deimling, "Zeros of accretive operators," Manuscripta Mathematica, vol. 13, pp. 365-374, 1974.

[8] R. H. Martin, "Differential equations on closed subsets of Banach spaces," Transactions of the American Mathematical Society, vol. 179, pp. 399-414, 1975.

[9] S. Reich, "An iterative procedure for constructing zeros of accretive sets in Banach spaces," Nonlinear Analysis. Theory, Method, \& Applications, vol. 2, no. 1, pp. 85-92, 1978.

[10] C. H. Morales, "Strong convergence of path for continuous pseudo-contractive mappings," Proceedings of the American Mathematical Society, vol. 135, no. 9, pp. 2831-2838, 2007.

[11] C. E. Chidume, "Global iteration schemes for strongly pseudocontractive maps," Proceedings of the American Mathematical Society, vol. 126, no. 9, pp. 2641-2649, 1998.

[12] C. E. Chidume and M. O. Osilike, "Nonlinear accretive and pseudo-contractive operator equations in Banach spaces," Nonlinear Analysis. Theory, Methods \& Applications, vol. 31, no. 7, pp. 779-789, 1998 .

[13] C. H. Morales and C. E. Chidume, "Convergence of the steepest descent method for accretive operators," Proceedings of the American Mathematical Society, vol. 127, no. 12, pp. 3677-3683, 1999.

[14] S. Reich, "Strong convergence theorems for resolvents of accretive operators in Banach spaces," Journal of Mathematical Analysis and Applications, vol. 75, no. 1, pp. 287-292, 1980. 
[15] A. Rafiq, "On Mann iteration in Hilbert spaces," Nonlinear Analysis. Theory, Methods \& Applications, vol. 66, no. 10, pp. 2230-2236, 2007.

[16] Y. Yao, Y.-C. Liou, and R. Chen, "Strong convergence of an iterative algorithm for pseudocontractive mapping in Banach spaces," Nonlinear Analysis. Theory, Methods \& Applications, vol. 67, no. 12, pp. 3311-3317, 2007.

[17] Y. Song and R. Chen, "Convergence theorems of iterative algorithms for continuous pseudocontractive mappings," Nonlinear Analysis. Theory, Methods \& Applications, vol. 67, no. 2, pp. 486497, 2007.

[18] A. Moudafi, "Viscosity approximation methods for fixed-points problems," Journal of Mathematical Analysis and Applications, vol. 241, no. 1, pp. 46-55, 2000.

[19] H.-K. Xu, "Viscosity approximation methods for nonexpansive mappings," Journal of Mathematical Analysis and Applications, vol. 298, no. 1, pp. 279-291, 2004.

[20] H.-K. Xu, "Iterative algorithms for nonlinear operators," Journal of the London Mathematical Society, vol. 66, no. 1, pp. 240-256, 2002.

[21] R. H. Martin,, "Differential equations on closed subsets of a Banach space," Transactions of the American Mathematical Society, vol. 179, pp. 399-414, 1973.

[22] V. Barbu and Th. Preocupanu, Convexity and Optimization in Banach Spaces, Editura Academiei R.S.R., Bucharest, Romania, 1978. 


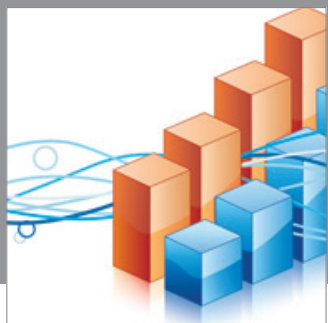

Advances in

Operations Research

mansans

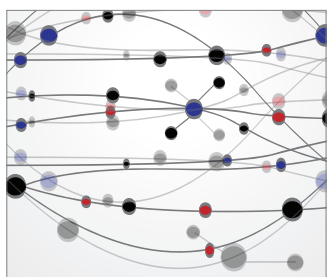

The Scientific World Journal
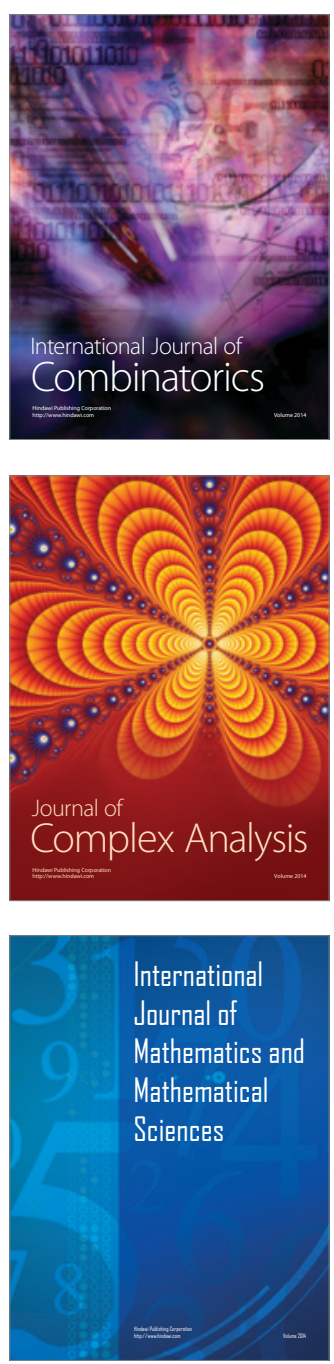
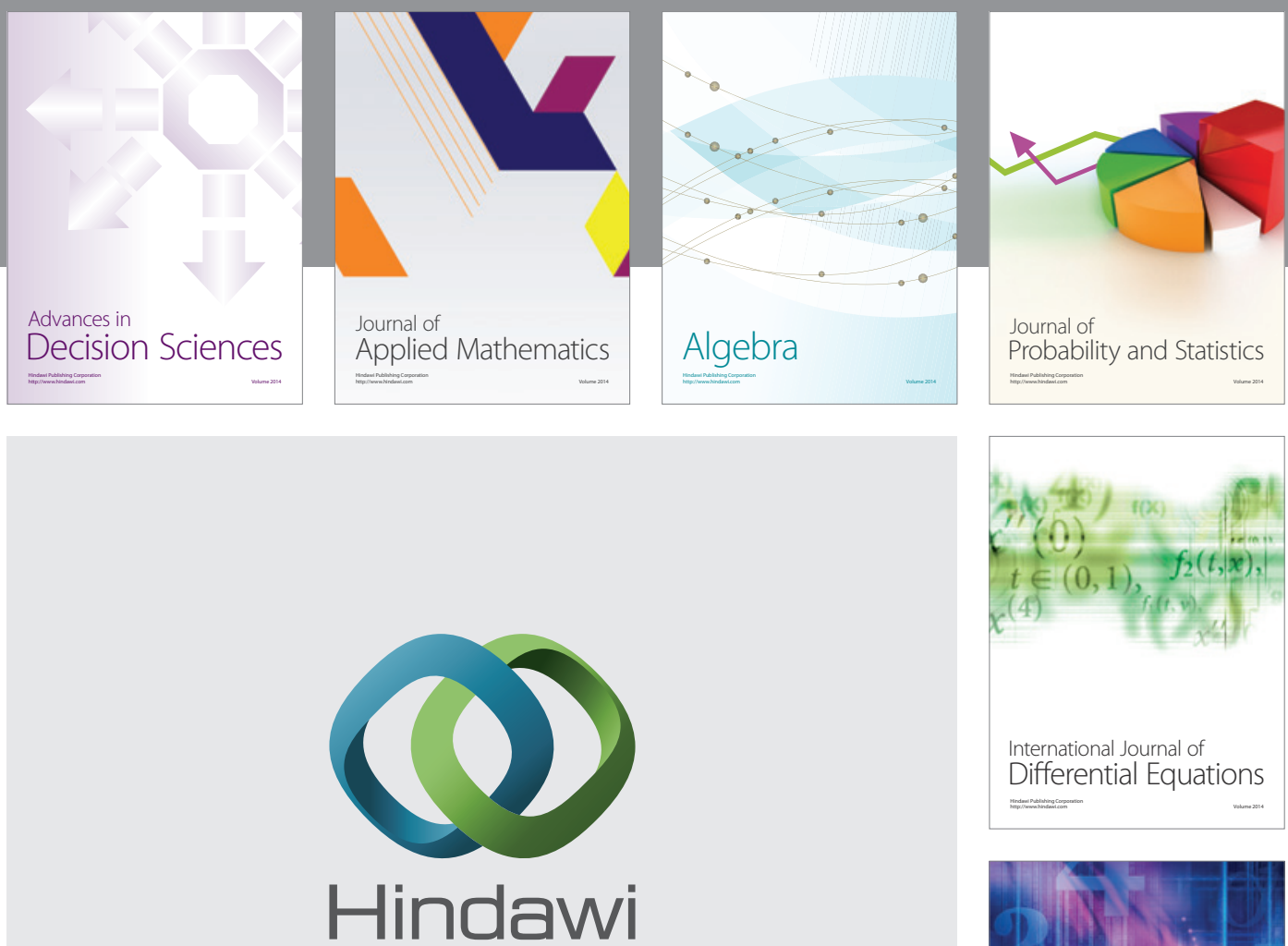

Submit your manuscripts at http://www.hindawi.com
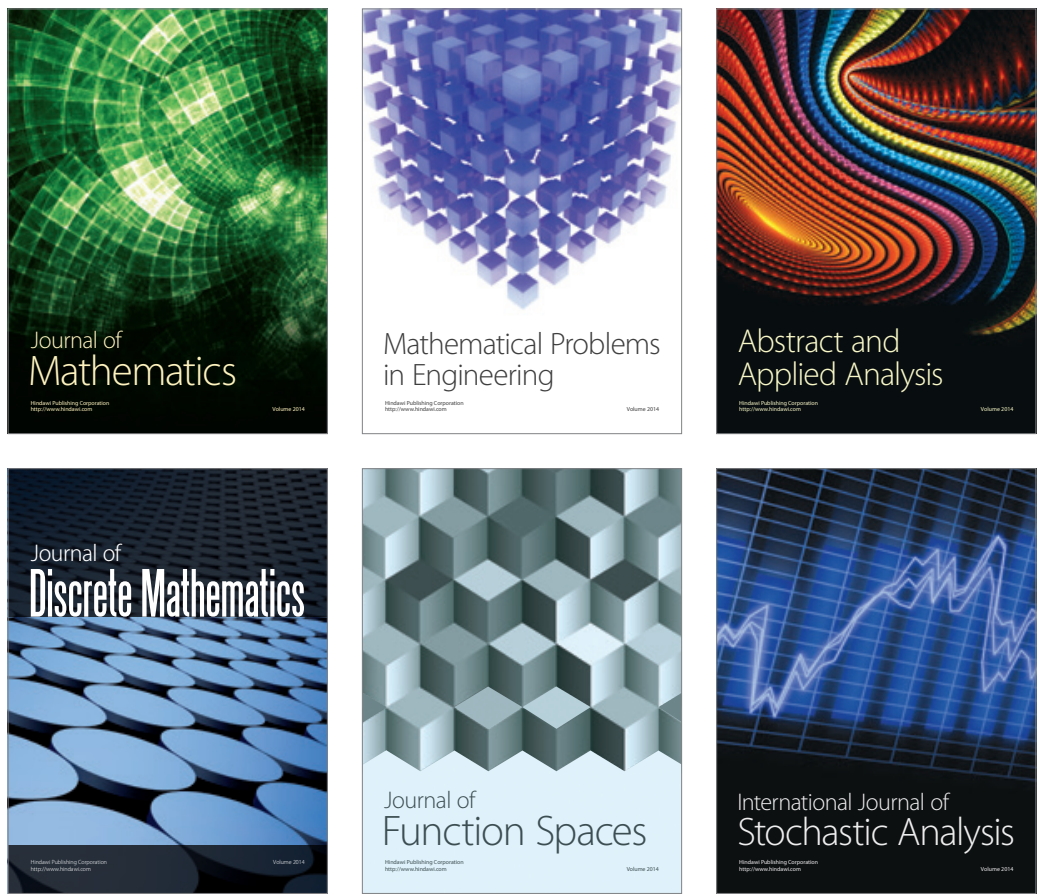

Journal of

Function Spaces

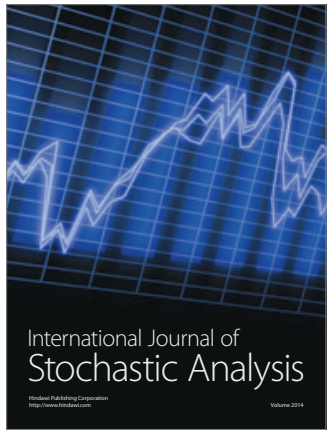

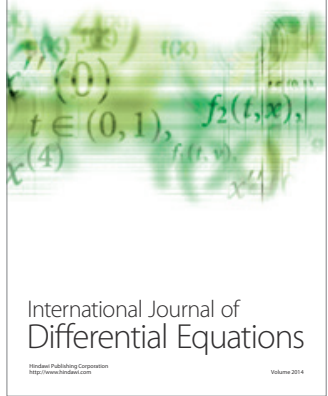
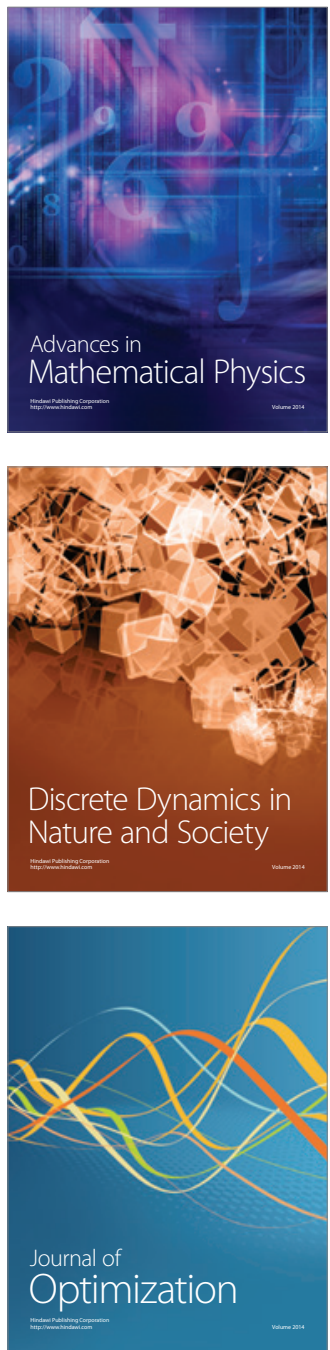